\title{
Pobreza e Meio Ambiente no Paraná ${ }^{40}$ Poverty and environment in Paraná
}

\author{
Adriana Stankiewicz Serra ${ }^{41}$ \\ Maurício Aguiar Serra
}

Artigo recebido em para publicação em mai/2013 e aceito para publicação em jun/2013

\section{Resumo}

Em função da importância de determinantes ambientais para várias dimensões de pobreza apontada pela literatura e das desigualdades socioeconômicas existentes no Paraná, o objetivo deste artigo é analisar a relação entre pobreza e meio ambiente nos municípios paranaenses. $O$ instrumento de análise é um indicador composto pelas duas temáticas, integradas por meio de análise de regressão, denominado Índice de Pobreza e Meio Ambiente (IPMA). Utilizando indicadores relativos ao tema do saneamento como proxies ambientais, os resultados comprovam o nexo pobreza- meio ambiente e, ao mesmo tempo, mostram diferenças significativas entre os municípios paranaenses.

Palavras-chave: Pobreza. Meio ambiente. Índice de Pobreza e Meio Ambiente (IPMA). Paraná.

\section{Abstract}

Because of the importance of environmental determinants for various dimensions of poverty suggested by the literature and also of the existing socioeconomic inequalities in Parana, the aim of this paper is to analyze the relationship between poverty and the environment in the municipalities of Parana. The analysis tool is an indicator composed by these two issues, which are integrated through regression analysis, is named Poverty and Environment Index (IPMA). By using indicators of sanitation as environmental proxies, the results not only confirm the poverty-environment nexus, but also show significant differences between municipalities in Paraná.

Keywords: Poverty. Environment. Poverty and Environment Index (IPMA). Paraná.

\section{Introdução}

As questões ambientais vêm ganhando cada vez mais destaque nos debates internacionais acerca do desenvolvimento. $\mathrm{O}$ crescimento econômico acelerado, associado à utilização indiscriminada de recursos naturais e intensificado após a Segunda Guerra Mundial, contribuiu não só para a geração de significativos impactos ambientais adversos, como também para a percepção de que a capacidade de suporte da Terra estava chegando ao seu limite, em função da poluição crescente do ar e da água e da própria exaustão dos recursos naturais.

Ao mesmo tempo, observou-se que o progresso econômico do pós-guerra, sem precedentes na história, aconteceu com a manutenção de fortes disparidades socioeconômicas entre países e dentro deles. Segundo os últimos dados disponíveis (UNITED NATIONS, 2012), quase 1,4 bilhão de pessoas nos países em desenvolvimento viviam em pobreza extrema em 2008 ( $24 \%$ da população), com menos de 1,25 dólar por dia.

\footnotetext{
${ }^{40}$ Uma versão ampliada deste artigo foi aceita para publicação pela Revista Planejamento e Políticas Públicas - PPP em 3 ago. 2012.

${ }^{41}$ Adriana Stankiewicz Serra: Doutoranda em Desenvolvimento Econômico pelo Instituto de Economia da Universidade Estadual de Campinas (IE/UNICAMP). E-mail: adrist@hotmail.com.
}

Maurício Aguiar Serra: Professor do Instituto de Economia da Universidade Estadual de Campinas (IE/UNICAMP). E-mail: mserra@eco.unicamp.br. 
Existe uma ampla literatura internacional evidenciando as conexões entre meio ambiente e pobreza. Além da sua contribuição direta para o bem-estar por meio de serviços essenciais à vida, o meio ambiente fornece os insumos materiais e energéticos para as atividades de produção. A degradação ambiental e o esgotamento dos recursos afetam a qualidade de vida da sociedade em geral, mas principalmente as condições das pessoas mais pobres, na medida em que elas estão mais expostas a ambientes de risco e muitas vezes dependem da natureza como fonte direta dos meios de subsistência - por exemplo, através da agricultura ou da pesca.

No Brasil, verifica-se uma carência de estudos empíricos das relações entre as dimensões ambientais e de pobreza. Este tema é de grande relevância tanto para o país quanto para o Estado do Paraná, devido às disparidades socioeconômicas existentes e às evidências de danos ambientais. No caso paranaense, a região formada pela aglomeração metropolitana de Curitiba, pelo entorno de Ponta Grossa e Paranaguá apresenta a maior concentração econômica e populacional do Estado. Por outro lado, municípios da região central e do Vale do Ribeira/Guaraqueçaba apresentam condições sociais bastante precárias e não têm indicadores econômicos de relevância (IPARDES, 2004, 2006).

Em 2009, havia no Paraná aproximadamente 1 milhão de pessoas pobres, seguindo o critério de pobreza como insuficiência de renda para atender a todas as necessidades básicas - alimentação, habitação, transporte, saúde, lazer, educação, etc. Essa população representava 9,5\% do total do Estado e $47,9 \%$ dos pobres da Região Sul. O número de indigentes (ou pessoas vivendo em condição de pobreza extrema) - aqueles cuja renda familiar per capita é inferior ao valor necessário para atender tão somente as necessidades mínimas de alimentação - era de 273 mil pessoas $(2,6 \%)^{42}$ (IETS, 2013).

O objetivo deste artigo é analisar a relação entre pobreza e meio ambiente no Estado do Paraná, tendo o município como unidade de análise. A investigação ao nível municipal, ainda que limitada pela disponibilidade de dados, se faz necessária para conhecer as diversas realidades em termos da falta de acesso a bens ambientais adequados, uma vez que medidas agregadas encobrem variações espaciais.

Para atingir o objetivo proposto, o artigo está estruturado em cinco seções. Após esta introdução, a segunda seção apresenta uma revisão da literatura sobre os vínculos existentes entre pobreza e meio ambiente. A terceira seção mostra o Índice de Pobreza Humana (IPH) adaptado aos municípios paranaenses. A quarta seção trata da construção de um indicador composto por dimensões ambientais e de pobreza, denominado Índice de Pobreza e Meio Ambiente (IPMA), que constitui o principal instrumento para analisar a relação entre as duas dimensões no Paraná. Por fim, a quinta seção traz as considerações finais.

\section{Os nexos entre pobreza e meio ambiente}

A importância das questões ambientais para o bem-estar humano tem sido ressaltada pela literatura econômica. $\mathrm{Na}$ discussões acerca das relações entre meio ambiente e pobreza, ganha importância a concepção de que os pobres são mais afetados pela deterioração ambiental, em função da sua maior dependência de recursos naturais para sobrevivência e da maior exposição a riscos (DASGUPTA, 1995, 1996; MARKANDYA, 2001). Ecossistemas degradados aumentam a fome e a vulnerabilidade, dificultando as possibilidades das pessoas mais pobres saírem da situação precária em que vivem (COMIM, 2008; DFID et al., 2002). Nesse sentido, o meio ambiente é uma peça-chave na elaboração de estratégias para redução da pobreza.

De acordo com o Banco Mundial (WORLD BANK, 2008), a redução da pobreza é um problema dividido em três partes: ela envolve a interrupção do declínio das pessoas na direção de uma situação de maior pobreza, a capacitação das pessoas para sair da condição de pobreza, e o impedimento de que as pessoas que não são pobres se tornem pobres. Na verdade, a redução da vulnerabilidade das pessoas é tão importante quanto a redução da pobreza.

Algumas definições precisam ser explicitadas de modo que os vínculos entre pobreza e meio ambiente possam ser analisados. Em primeiro lugar, a pobreza é entendida como uma privação inaceitável de bem-estar multidimensional, seguindo a abordagem das organizações internacionais.

\footnotetext{
${ }^{42}$ Valores das linhas de pobreza e de indigência estimadas por Sonia Rocha. Indicadores de pobreza e de indigência disponíveis em http://www.iets.org.br.
} 
Segundo, o meio ambiente é definido por diferentes ecossistemas ${ }^{43}$ e serviços, sendo que os ecossistemas podem variar em escala temporal, espacial e administrativa, e também entre escalas. As múltiplas dimensões e a complexidade dos fenômenos resultam em grande dificuldade para identificar as relações de causalidade (DURAIAPPAH, 1998; MARKANDYA, 2001).

Um exame detalhado da literatura sobre a relação pobreza-degradação ambiental foi realizado por Duraiappah (1998). Este trabalho foi estruturado em quatro possíveis relações de causalidade, que podem coexistir: (a) pobreza exógena (causada por fatores não ambientais) causa degradação ambiental; (b) o poder, a riqueza e a ganância ocasionam a degradação ambiental; (c) falhas institucionais e de mercado são causas primárias de degradação ambiental; e (d) a degradação ambiental causa pobreza, sendo que esta última possibilidade implica a presença de uma das relações anteriores, ou de uma combinação entre elas. A retroalimentação também é plausível: o ambiente degradado causa pobreza que, por sua vez, resulta em maiores danos ambientais.

Há consideráveis evidências apontadas por Duraiappah (1998) para se refutar a hipótese hegemônica de que os impactos ambientais negativos são gerados pela pobreza. Na realidade, o meio ambiente é inicialmente degradado por aqueles que concentram maior riqueza e poder, o que ocorre quando há falhas institucionais e de mercado. Barbier (2005) também defende que a relação ocorre da melhoria na gestão ambiental para o desenvolvimento econômico e o bem-estar, e não o contrário.

É interessante notar que o Relatório de Desenvolvimento Humano de 1990 (PNUD, 1990) já destacava a degradação ambiental como um dos obstáculos à melhoria da vida humana, o que constitui um verdadeiro desafio para todos os países, inclusive os de maior renda. Os principais fatores mencionados foram os riscos à saúde, decorrentes da poluição industrial e desastres ambientais, além do desmatamento, da carência de acesso à água e instalações sanitárias adequadas, da falta de tratamento de esgoto, do envenenamento por pesticidas e da poluição atmosférica. Segundo a Organização Mundial da Saúde (OMS), o custo de medidas para remediar a degradação ambiental e eliminar os significativos riscos à saúde pública é superior ao custo de prevenção.

A Figura 1 possibilita uma melhor visualização da forma como a gestão ambiental pode contribuir para a redução da pobreza. Torna-se importante ressaltar aqui que a dimensão saúde envolve algumas questões essenciais na relação entre pobreza e meio ambiente, tais como água potável, saneamento, poluição do ar e doenças transmitidas por vetores.

${ }^{43}$ Ecossistemas são complexos dinâmicos de comunidades vegetais, animais e de microrganismos e seu meio inorgânico, que interagem como uma comunidade funcional, em um determinado espaço, de dimensões variáveis (IBGE, 2008, p. 442). 
Exemplos de determinantes ambientais

Dimensões de pobreza

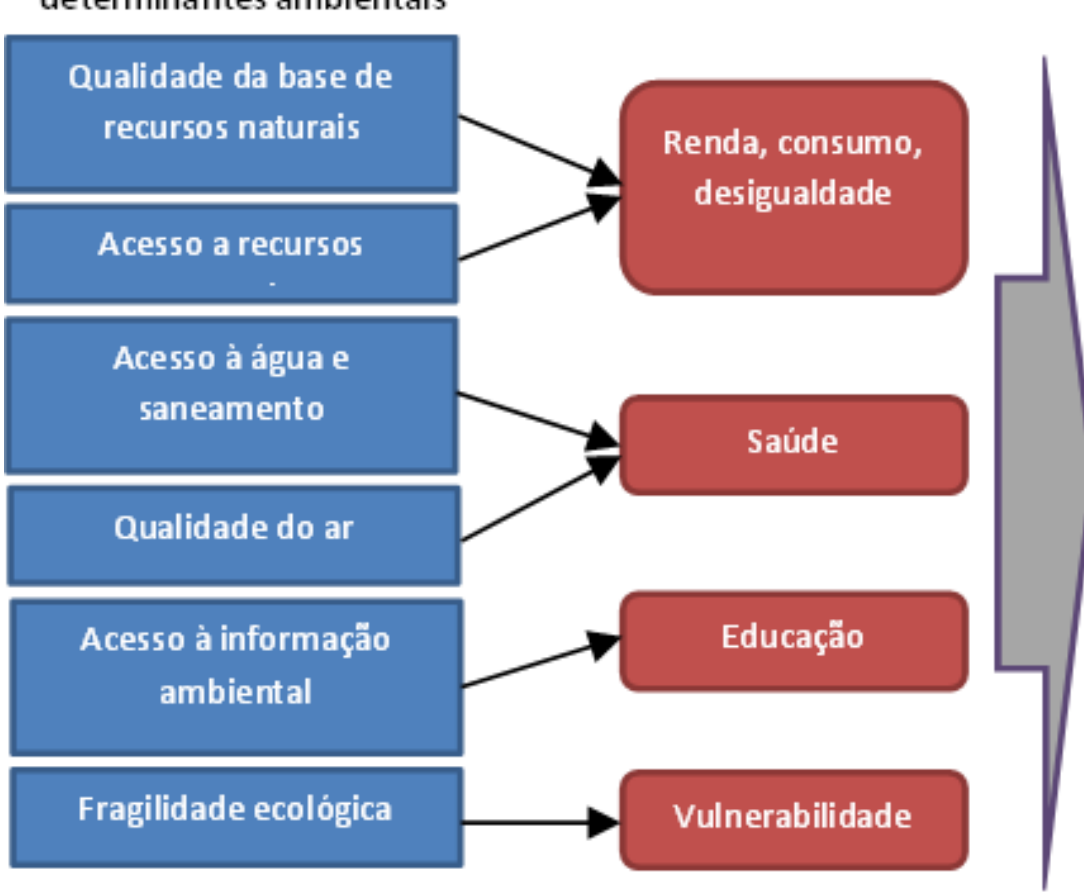

Figura 1 - Dimensões e determinantes da pobreza Fonte: Adaptado de Bojö et al. (2001)
Elementos de bem-estar

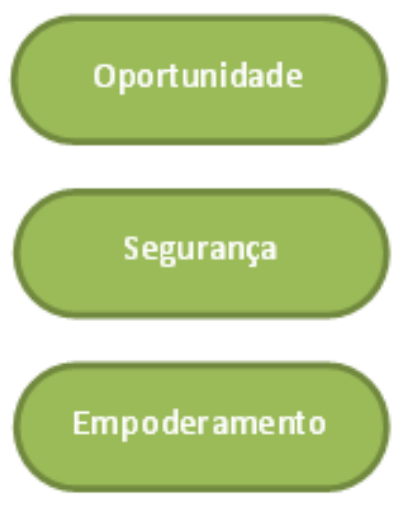

Um aspecto importante a ser observado é como as dimensões da pobreza mais afetadas pelo meio ambiente - saúde, oportunidade econômica, segurança e empoderamento - se relacionam com os principais determinantes ambientais. Com base na Figura 1, podem ser destacadas quatro importantes conexões: (a) entre meio ambiente e saúde; (b) entre meio ambiente e oportunidade econômica; (c) entre meio ambiente e segurança; e (d) entre meio ambiente e empoderamento.

Em relação à primeira conexão, deve-se sublinhar que a poluição do ar e da água pode provocar, respectivamente, infecções respiratórias e diarreia, que estão entre as principais causas de mortalidade entre crianças pobres. Outros fatores, aos quais as famílias pobres costumam estar mais expostas, são a água parada e o acúmulo de lixo próximo às residências, condições favoráveis à propagação de doenças de transmissão vetorial, como a malária e a dengue.

Os principais fatores de risco à saúde nos países em desenvolvimento, de acordo com a OMS (WHO, 2002), são: desnutrição, sexo inseguro, água contaminada, falta de saneamento e higiene, e fumaça no interior dos ambientes proveniente de combustíveis sólidos. A prevalência da desnutrição está associada não somente à insegurança alimentar, mas também a um ambiente insalubre, uma vez que a falta de higiene é um fator determinante na desnutrição entre as crianças (WORLD BANK, 2008).

Já no que tange à segunda relação, observa-se que pode ser estabelecida através de três canais: (a) renda, consumo e desigualdade; (b) saúde; e (c) educação. $O$ acesso aos recursos naturais e sua qualidade são fatores importantes, sobretudo para os pobres das áreas rurais, uma vez que a alimentação e a renda muitas vezes dependem diretamente dos ecossistemas. A carência de serviços básicos (energia, água e saneamento) também limita as oportunidades produtivas, além da prestação de serviços de saúde e educação, pela dificuldade de atrair profissionais qualificados para as áreas rurais e as comunidades urbanas pobres (DFID et al., 2002; UNDP et al., 2005). O tempo gasto quando há necessidade de coleta de água e de lenha, que poderia ser dedicado à educação e atividades geradoras de renda, é outro exemplo bastante ilustrativo. Além desses aspectos, Veiga (2007) ressalta a importância da educação científica, que depende de serviços básicos, como energia e saneamento. De fato, a compatibilidade entre crescimento econômico e sustentabilidade ambiental, redução da pobreza e melhor qualidade de vida para o conjunto da sociedade depende consideravelmente de investimentos em ciência, tecnologia e inovação. 
Quanto à terceira conexão, a questão central é a redução da vulnerabilidade dos mais pobres em relação aos choques macroeconômicos e desastres naturais. As famílias pobres são mais vulneráveis pela dependência direta dos recursos naturais para sobrevivência e pela moradia em áreas marginais degradadas, rurais ou urbanas. Por isso, são mais afetadas pela ocorrência de secas (no caso da agricultura como atividade principal) e inundações. Barbier (2005) ressalta a forte associação entre pobreza extrema e concentração de pessoas em áreas vulneráveis nos países em desenvolvimento, tendo como exemplos regiões sem acesso a sistemas de irrigação, solos impróprios para agricultura, terrenos com declives acentuados e sistemas florestais frágeis.

Por fim, a quarta relação diz respeito à autonomia dos pobres e depende, fundamentalmente, da educação e do acesso à informação ambiental. Dessa forma, a comunidade pode ter participação na tomada de decisões, contribuindo para a redução das desigualdades e o uso sustentável dos recursos (BOJÖ et al., 2001).

Não se pode deixar de chamar a atenção para o fato de que todas as conexões acima mencionadas estão relacionadas às três dimensões essenciais do desenvolvimento e da pobreza humana, ou seja, vida longa e saudável, nível de conhecimento e nível de vida digno (PNUD, 1990, 1997). Quando insuficientes, em quantidade ou qualidade, os fatores ambientais constituem formas de privação de liberdade de escolha das pessoas para realizarem aquilo que elas valorizam (SEN, 2000).

Com base em uma amostra de sessenta países em desenvolvimento que tinham uma parte considerável de suas populações (de 20 a 70\%) vivendo em ambientes frágeis e também um elevado percentual (45,3\% em média) delas em pobreza extrema, Barbier (2008) mostrou que a incidência da pobreza rural aumentava na medida em que os países em desenvolvimento tinham maior concentração de suas populações em terras frágeis.

Dasgupta et al. (2005), ao analisarem o nexo pobreza-meio ambiente em três países pobres do sudoeste asiático - Camboja, Laos e Vietnam -, apontaram para o fato de que as populações rurais pobres destes países estavam agrupadas na maior parte das terras marginais, o que corrobora a assertiva de Barbier, muito embora isso esteja longe de se constituir uma tendência porque há entre os países diferenças consideráveis.

Nos países em desenvolvimento, os esforços para compatibilizar as pressões do desenvolvimento com a preservação ambiental resultaram em alguns mecanismos de mercado, que vão desde os instrumentos fiscais, tais como o Imposto sobre Circulação de Mercadorias e Serviços (ICMS) Ecológico no Brasil, até o sequestro de carbono, sendo o pagamento pelos serviços ambientais (PSA) um deles (PAGIOLA, BISHOP e LANDELL-MILLS, 2004). Na realidade, o PSA, cujo foco é o financiamento da conservação ambiental, obedece a um princípio bem simples: quem se beneficia dos serviços proporcionados pelo meio ambiente deve pagar por eles, enquanto quem contribui para gerar estes serviços deve ser pago por eles (WORLD BANK, 2008).

Segundo Barbier (2008), o PSA pode mitigar a pobreza de três formas: (a) canalizando os pagamentos pelos serviços ambientais diretamente para as populações rurais pobres que geram estes serviços, proporcionando desta maneira uma renda monetária; (b) recebendo ou não os pagamentos diretos, as populações rurais pobres podem se beneficiar indiretamente de qualquer melhoria resultante na provisão dos serviços ambientais; e (c) as populações rurais pobres também podem ganhar com as oportunidades econômicas extras geradas pelos esquemas de pagamento, tais como o emprego adicional criado pelo reflorestamento.

As relações entre meio ambiente e pobreza são dinâmicas e específicas para cada contexto, em função da localização geográfica e das características econômicas, sociais e culturais. Enquanto nas áreas rurais as principais preocupações se referem ao acesso e à qualidade de recursos naturais (terra, água, florestas, biodiversidade, etc.), nas áreas urbanas o acesso à água, energia, saneamento e coleta de lixo estão entre as questões mais críticas (DFID et al., 2002). Nesse sentido, a ampliação do acesso aos recursos ambientais é uma medida importante na elaboração de estratégias de combate à pobreza.

Embora haja uma crescente literatura internacional acerca dos vínculos entre pobreza e meio ambiente, o mesmo não acontece no Brasil, que ainda carece de trabalhos que aprofundem a compreensão desta importante e atual temática. Entretanto, alguns se destacam e, por conseguinte, merecem ser mencionados.

As políticas de conservação da Amazônia brasileira foram analisadas por Fearnside (2003), que destacou os conflitos de interesse entre os principais agentes. A negociação com povos indígenas foi apontada como uma das questões mais críticas para o futuro dos ecossistemas da região, uma vez que suas terras correspondem a uma área superior à área total das unidades de conservação, e essa população pode responder a incentivos econômicos que resultem em desmatamento. A redução da 
pobreza em unidades de conservação é importante do ponto de vista ambiental, sobretudo para a manutenção da biodiversidade.

Hecht, Anderson e May (1988 apud DASGUPTA, 2001) descreveram qualitativamente a importância do extrativismo de babaçu para a população sem-terra do Maranhão, mostrando a relevância da atividade como fonte de renda para a população mais pobre no período de entressafra agrícola, especialmente para as mulheres.

As principais causas de desmatamento nos municípios da Amazônia Legal brasileira foram o objeto de análise de Diniz et al. (2009). Os resultados empíricos mostraram a existência de causalidade bidirecional entre desmatamento e variáveis agropecuárias (áreas de lavoura permanente e temporária; tamanho do rebanho bovino). Em relação às variáveis socioeconômicas, os autores encontraram causalidade unidirecional do desmatamento para a matrícula no ensino fundamental regular, e bidirecional entre o desmatamento e a educação de adultos.

Chiarini (2008) analisou a conexão entre pobreza e meio ambiente na área urbana. Para tanto, realizou uma análise estatística tendo o Índice de Desenvolvimento Humano (IDH) como proxy para a pobreza, e como proxies para degradação ambiental o percentual de domićlios sem acesso a saneamento e o percentual de domicílios com acesso ao serviço de coleta de lixo. Os resultados obtidos apontaram para o fato de que o vínculo pobreza-meio ambiente possui uma dupla relação, ou seja, a pobreza afeta o meio ambiente, assim como o meio ambiente impacta a pobreza.

\section{Índice de pobreza humana para os municípios paranaenses}

De modo similar à adaptação do IDH para os municípios brasileiros (IDH-M) ${ }^{44}$, Rolim (2005) construiu um índice de pobreza humana municipal (IPH-M). Mantidas as mesmas dimensões do IPH-1 (países em vias de desenvolvimento), foram realizadas algumas adaptações nos indicadores, tendo como fonte a base de dados disponível no Atlas de Desenvolvimento Humano no Brasil (PNUD, 2003).

A fórmula de cálculo do IPH-M é a mesma do $\mathrm{IPH}^{45}$ :

$$
I P H M=\left[\frac{1}{3}\left(P_{1}^{3}+P_{2}^{3}+P_{3}^{3}\right)\right]^{1 / 3}
$$

onde $P_{1}$ é o índice de longevidade (probabilidade de morrer antes dos 40 anos), $P_{2}$ é o índice de educação (percentual de pessoas de 15 anos ou mais analfabetas) e $P_{3}$ é o índice relativo ao padrão de vida (média aritmética simples entre o percentual de pessoas que vivem em domicílios sem água encanada e a mortalidade com até 5 anos de idade). O IPH-M varia entre 0 e 100 e, ao contrário do IDH$M$, é melhor quanto mais próximo de zero. O índice pode ser visto como uma proxy da incidência de pobreza nos municípios (Rolim, 2005).

O Gráfico 1 mostra a distribuição dos municípios paranaenses por intervalos de pobreza humana, em dez estratos do IPH-M, a partir da aplicação da metodologia proposta por Rolim (2005). Pode-se observar uma concentração do índice em apenas três estratos, não havendo municípios classificados nos estratos correspondentes às piores condições.

\footnotetext{
${ }^{44} \mathrm{O}$ IDH-M é calculado a partir de indicadores apurados diretamente dos censos demográficos do IBGE e resulta da combinação das mesmas três dimensões do IDH - longevidade, educação e renda -, com adaptação de indicadores para as duas últimas dimensões. O índice de longevidade é obtido a partir do indicador esperança de vida ao nascer. O índice de educação é a média de dois indicadores: taxa de alfabetização de adultos (peso 2) e taxa bruta de frequência combinada (peso 1), em substituição à taxa bruta de matrícula combinada, empregada no IDH. A renda familiar per capita média do município substituiu o PIB per capita no cálculo do índice de renda. O IDH-M é a média aritmética simples dos índices de longevidade, educação e renda (PNUD, 2003). Da mesma forma que o IDH, o IDH-M varia entre 0 e 1. Quanto mais próximo de 1, maior é o nível de desenvolvimento humano do município.

${ }^{45}$ Com a mesma base teórica do IDH, o IPH foi apresentado no Relatório de Desenvolvimento Humano de 1997 (PNUD, 1997), composto pelos seguintes indicadores: (a) percentual de pessoas com probabilidade ao nascer de não viver até os 40 anos; (b) percentual de adultos analfabetos; (c) percentual da população sem acesso à água tratada; e (d) percentual de crianças desnutridas abaixo de 5 anos.
} 


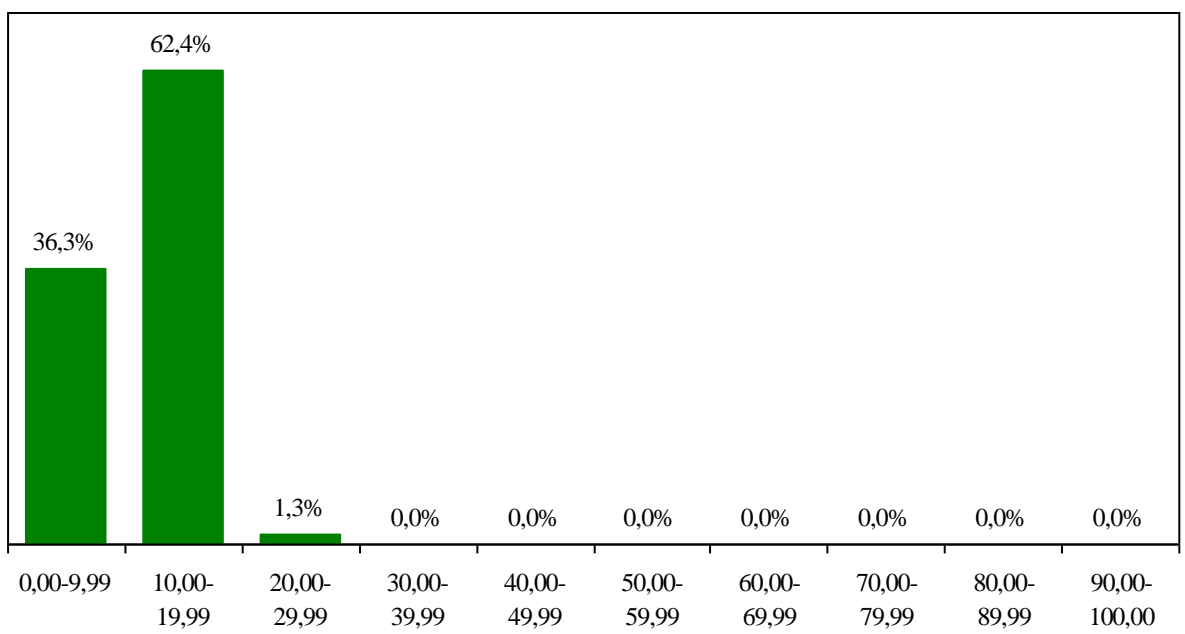

IPH-M 2000

Gráfico 1 - Distribuição dos municípios por intervalos de pobreza humana - Paraná (2000) Fonte: PNUD (2003).

Elaboração dos autores.

Os cinco piores colocados no ranking do IPH-M, classificados no terceiro estrato do gráfico 3 (1,3\% dos municípios paranaenses) são: Laranjal $(21,35)$, Ortigueira $(21,25)$, Tunas do Paraná $(20,52)$, Godoy Moreira $(20,48)$ e Mato Rico $(20,04)$. São municípios de pequeno porte populacional (população inferior a 20.000 habitantes) e com baixo grau de urbanização, localizados nas regiões reconhecidamente mais carentes: região central do estado (Laranjal, Ortigueira, Godoy Moreira e Mato Rico) e Vale do Ribeira (Tunas do Paraná).

No extremo oposto, para os vinte melhores colocados no ranking do IPH-M, os municípios da Mesorregião Oeste Paranaense destacam-se nas melhores posições (dez dos vinte municípios com menor IPH-M). A distribuição dos municípios por intervalos do IPH-M é ilustrada na Figura 2.

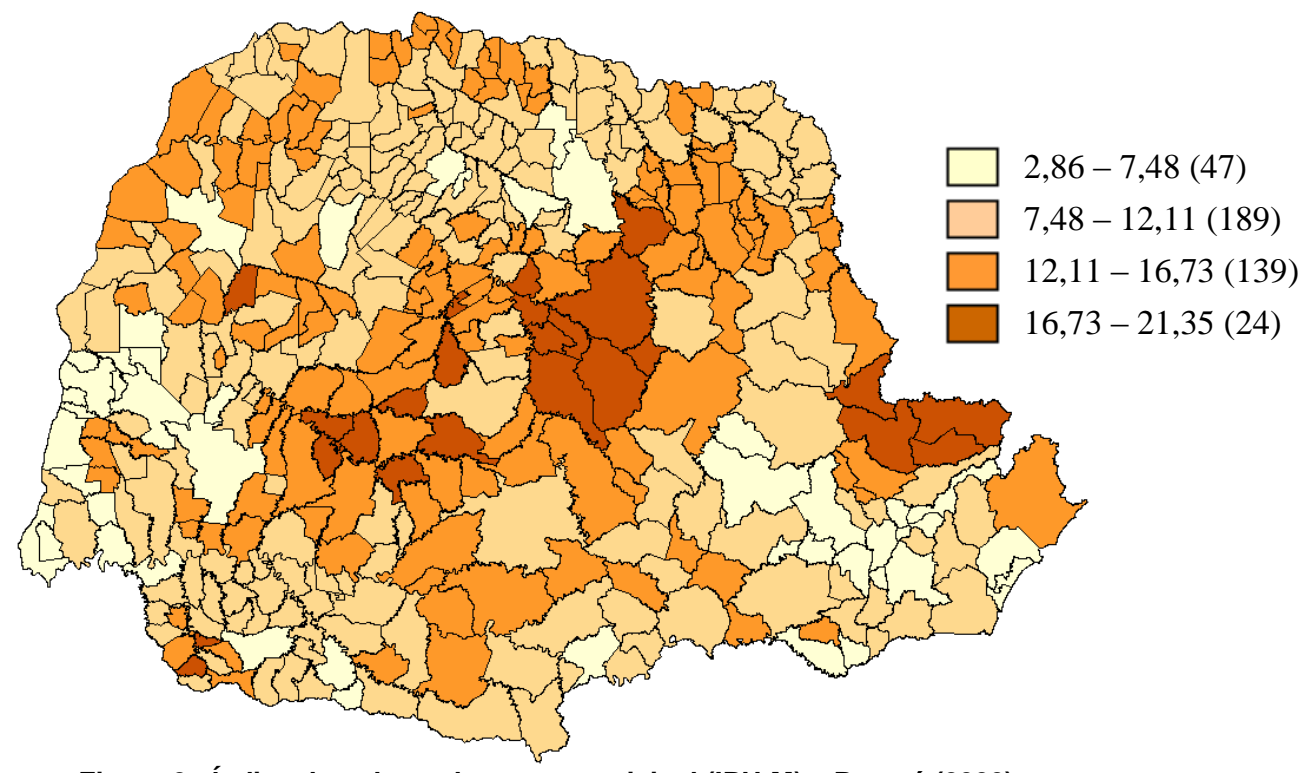

Figura 2 - Índice de pobreza humana municipal (IPH-M) - Paraná (2000) Fonte: PNUD (2003).

Elaboração dos autores.

Obs.: mapa construído com auxílio do programa OpenGeoDa (Geoda, 2009).

$\mathrm{Na}$ distribuição por mesorregiões, aquelas que tiveram maior parcela dos seus municípios classificados no estrato inferior (IPH-M entre 0,00 e 9,99) foram: Centro Oriental, Oeste, Sudoeste e 
Sudeste paranaense, além da Região Metropolitana de Curitiba. Com maior percentual dos municípios classificados no segundo estrato (IPH-M entre 10,00 e 19,99), que concentrou $62,4 \%$ dos municípios paranaenses, ficaram as mesorregiões Noroeste, Centro Ocidental, Norte Central, Norte Pioneiro e Centro-Sul Paranaense.

\section{Construção de um índice de pobreza e meio ambiente para os municípios paranaenses}

Para analisar as relações entre dimensões ambientais e de pobreza no Paraná, foi calculado um índice para os municípios, tendo como referência principal a metodologia proposta no relatório Poverty \& environment indicators (COMIM, 2008), preparado pela equipe do Capability and Sustainability Centre (CSC) da Universidade de Cambridge, em parceria com o Programa das Nações Unidas para o Desenvolvimento e o Programa das Nações Unidas para o Meio Ambiente (PNUD-PNUMA). O relatório apresenta os resultados do modelo aplicado a países para demonstração, mas ressalta que o método foi concebido para aplicação local, considerado o ideal para o estudo do grau em que o meio ambiente afeta a pobreza, levando em conta as especificidades de cada localidade.

Em função das significativas desigualdades socioeconômicas existentes entre os municípios paranaenses e da limitada disponibilidade de dados, algumas mudanças metodológicas tiveram de ser realizadas e serão explicitadas ao longo desta seção. Adaptações se tornam necessárias, principalmente, pela escassez de indicadores ambientais adequados, problema que é ainda maior no âmbito local.

\section{Metodologia}

A metodologia proposta (COMIM, 2008) para a elaboração de um indicador composto de pobreza e meio ambiente recomenda o uso de fatores de ajuste e análise de regressão, assumindo que a relação de causalidade existente é da degradação ambiental para a pobreza. Em outras palavras, as dimensões de pobreza representam a variável dependente, e os indicadores ambientais as variáveis explicativas:

$$
\text { Pobreza }=f(\text { variáveis ambientais }+ \text { variáveis de controle })
$$

Embora não sejam foco da análise, as variáveis de controle podem ajudar a explicar a variável dependente. No modelo especificado por Comim (2008), por exemplo, foram incluídos o PIB e gastos públicos em saúde e educação.

Além de serem relacionados, no sentido de associarem duas dimensões (pobreza e meio ambiente), os indicadores propostos se caracterizam pela objetividade e pela multidimensionalidade. Desta forma, evita-se o viés de interpretação decorrente de visões subjetivas a respeito da pobreza, e também análises restritas, como a pobreza medida apenas pelo critério de insuficiência de renda.

Os fatores de ajuste são calculados para integrar as dimensões de pobreza e meio ambiente, alterando as medidas de pobreza (para mais ou para menos) de acordo com a natureza e extensão dos problemas ambientais. São obtidos pela multiplicação dos indicadores ambientais pelo grau de associação entre as duas dimensões (coeficientes obtidos nas regressões).

A construção dos indicadores contempla os seguintes passos:

a) coleta de dados;

b) seleção dos dados relevantes (nesta pesquisa, através de matriz de correlação);

c) harmonização das escalas ambientais, alinhando a direção das variáveis ambientais (quanto mais próximo de 1 , pior o indicador);

d) divisão das variáveis ambientais pelos critérios de sustentabilidade ou, na ausência destes critérios, obtenção de médias para saber sua posição relativa;

e) execução de uma regressão para cada componente de pobreza, incluindo como fatores explicativos todas as variáveis ambientais, mais as variáveis de controle:

- seleção dos indicadores estatisticamente significativos;

- verificação dos coeficientes de associação (das regressões);

- testes de multicolinearidade, $R^{2}$, heterocedasticidade e valores $t$ de significância estatística (dados em corte transversal); 
f) após as regressões, retorno à base de dados consolidada e construção de novas colunas com aquelas variáveis que são estatisticamente significativas;

g) normalização das variáveis (escalas [0-1]), a fim de possibilitar a sua integração;

h) cálculo dos fatores de ajuste:

- variáveis ambientais relevantes do passo (e);

- coeficientes de regressão do passo (e);

- multiplicação das variáveis ambientais pelos coeficientes de regressão para obter novas variáveis relacionadas de pobreza e meio ambiente;

i) agregação dos indicadores em dimensões: depois de colocar todos os indicadores de pobreza e meio ambiente em escalas [0-1], obter médias simples de acordo com as diferentes regiões para os indicadores relevantes; e

j) elaboração de rankings e interpretação (quanto mais próximo de 1, pior o indicador).

O indicador resultante, chamado de poverty \& environment (P\&E) indicator, mostra o grau em que o meio ambiente afeta a pobreza:

$P \& E$ indicator $=(\underbrace{}_{\text {Fator de ajuste }}$

Torna-se importante enfatizar que a finalidade desses indicadores compostos é incluir uma perspectiva ambiental na investigação da pobreza, com base na literatura existente sobre o nexo pobreza-meio ambiente. Portanto, não há pretensão de se obter uma medida abrangente de qualidade de vida.

\section{Seleção de Variáveis}

Seguindo as recomendações de Comim (2008) para o desenvolvimento de indicadores de pobreza e meio ambiente, o levantamento de dados buscou contemplar os seguintes fatores: acesso e qualidade da água; degradação do solo (incluindo risco de erosão); estimativas de biocapacidade e vulnerabilidade a riscos naturais; disponibilidade e uso de energia; qualidade do ar; desnutrição e medidas antropométricas; taxas de mortalidade; e educação.

Nesta primeira etapa, foram pesquisadas diversas bases de dados disponíveis na internet. Visto que existe no Brasil uma vasta base de dados socioeconômicos, cuja principal fonte é o Instituto Brasileiro de Geografia e Estatística (IBGE), o desafio foi levantar as variáveis ambientais disponíveis para os municípios. Foram examinados os indicadores de desenvolvimento sustentável (IDSs) do IBGE, os indicadores dos Objetivos de Desenvolvimento do Milênio (ODMs) e do Atlas de Desenvolvimento Humano no Brasil do PNUD, além de outros dados de acesso público destas e de outras instituições, como o Instituto Paranaense de Desenvolvimento Econômico e Social (Ipardes), o Instituto Ambiental do Paraná (IAP) e a Companhia de Saneamento do Paraná (Sanepar).

Embora relevantes, a maior parte das fontes mencionadas apresenta problemas para a realização de uma análise no âmbito municipal. Os IDSs do IBGE, por exemplo, são medidas demasiadamente agregadas, que ocultam variações espaciais importantes. Para este estudo, o Atlas de Desenvolvimento Humano no Brasil (PNUD, 2003) mostrou ser a fonte mais adequada. Elaborado a partir dos censos demográficos de 1991 e 2000 do IBGE, o Atlas apresenta indicadores agrupados pelos temas: demografia, educação, renda, habitação, vulnerabilidade, população e desenvolvimento humano. O tema habitação abrange indicadores de acesso a bens e serviços básicos, que podem ser empregados como proxies ambientais para o estudo do nexo pobreza-meio ambiente (por exemplo, variáveis referentes a saneamento e energia).

Para auxiliar a seleção das variáveis a serem incluídas no modelo proposto, foi elaborada uma matriz de correlação ${ }^{46}$. Inicialmente, foram avaliadas 26 variáveis, agrupadas nas dimensões que

\footnotetext{
${ }^{46} \mathrm{O}$ coeficiente de correlação mede o grau de associação linear entre duas variáveis, não implicando qualquer relação de causa e efeito. Situa-se entre os limites de -1 e +1 , sendo que -1 indica associação negativa perfeita e, +1 , associação positiva perfeita (GUJARATI, 2006).
} 
compõem o IDH e o IPH (longevidade, conhecimento e padrão de vida decente), além de pobreza e desigualdade de renda, proxies ambientais e variáveis de controle.

Como proxies ambientais, foram verificados indicadores de acesso a bens e serviços básicos: banheiro e água encanada, energia elétrica e serviço de coleta de lixo, este último disponível apenas para domicílios urbanos. Dada a elevada correlação entre, por um lado, a existência de banheiro e água encanada e, por outro, de energia elétrica nos domicílios $(0,8401)$, aliada ao destaque dado na literatura aos problemas ambientais decorrentes da falta de acesso à água limpa e ao saneamento adequado, e os consequentes danos à população, principalmente de baixa renda, o artigo está limitado ao tema saneamento. Assim sendo, os indicadores escolhidos como proxies ambientais para as regressões (variáveis explicativas) foram o percentual de pessoas que vivem em domicílios com banheiro e água encanada e o percentual de pessoas que vivem em domicílios urbanos com coleta de lixo posteriormente, multiplicado pela participação da população urbana no município, para evitar distorções em função dos diferentes graus de urbanização.

As variáveis de controle também foram selecionadas com base na matriz de correlação. Em relação ao modelo estimado por Comim (2008) e aplicado aos países, o PIB per capita foi substituído pela renda familiar per capita média mensal, seguindo a adaptação feita pelo PNUD (2003) para o cálculo do IDH-M. Além disso, a correlação entre a renda per capita e as dimensões de pobreza foi, em todos os casos, superior à correlação entre PIB per capita e pobreza ${ }^{47}$.

As despesas com saúde e educação, divulgadas pela Secretaria do Tesouro Nacional do Ministério da Fazenda, apresentaram correlação fraca com as variáveis dependentes do modelo. Como alternativa, foram investigados os seguintes indicadores: número de médicos residentes por mil habitantes; percentual de enfermeiros residentes com curso superior; percentual de professores do fundamental residentes com curso superior; e percentual de mulheres sem instrução e com menos de um ano de estudo. Os dois primeiros apresentaram correlação fraca e, por isso, foram descartados. Os últimos foram selecionados como variáveis de controle, juntamente com a renda per capita, tendo apresentado grau médio de correlação com as dimensões de pobreza. $O$ indicador referente à educação feminina foi obtido do IBGE (2009) e incluído na análise em função da sua reconhecida influência sobre as condições de saúde da família e, principalmente, da relação com a mortalidade infantil.

A matriz de correlação ${ }^{48}$ foi elaborada para diversas variáveis de desenvolvimento e pobreza que podem ser utilizadas no modelo como variáveis dependentes, além das variáveis ambientais e de controle pré-selecionadas (variáveis explicativas), sendo todas referentes ao ano $2000^{49}$, conforme relacionado a seguir:

a) Desenvolvimento humano: esperança de vida ao nascer; taxa bruta de frequência à escola; taxa de alfabetização de adultos ${ }^{50}$; e percentual de crianças de 7 a 14 anos que estão frequentando o curso fundamental ${ }^{51}$.

b) Pobreza humana: probabilidade de sobrevivência até 40 anos; percentual de pessoas de 15 anos ou mais analfabetas; mortalidade até 5 anos de idade.

c) Pobreza e desigualdade de renda: percentual da renda apropriada pelos $20 \%$ mais pobres da população; intensidade da pobreza ${ }^{52}$; e percentual de pessoas com renda per capita abaixo de $R \$ 75,50^{53}$.

\footnotetext{
${ }^{47}$ Por exemplo, em relação à mortalidade até 5 anos de idade, o coeficiente foi de $-0,4141$ para a renda e de $-0,1984$ para o PIB.

48 A matriz completa não é apresentada devido à limitação de espaço.

${ }^{49}$ Até a conclusão deste artigo, o Atlas de Desenvolvimento Humano 2013 ainda estava sendo produzido pelo PNUD Brasil, com base nos dados do Censo 2010 e lançamento previsto para o primeiro semestre de 2013.

${ }^{50}$ Percentual com idade a partir de 15 anos.

${ }^{51}$ Variável relacionada à taxa bruta de frequência à escola, componente do IDH que considera os níveis de ensino fundamental, médio e superior.
} 
d) Meio ambiente: percentual de pessoas que vivem em domicílios com banheiro e água encanada ${ }^{54}$; e percentual de pessoas que vivem em domicílios urbanos com serviço de coleta de lixo ${ }^{55}$.

e) Variáveis de controle: renda per capita; percentual de professores do ensino fundamental residentes com curso superior; e percentual de mulheres sem instrução e com menos de um ano de estudo.

A correlação entre as proxies ambientais e as variáveis das dimensões de desenvolvimento e pobreza selecionadas é, na maior parte, significativa ao nível de $1 \%$. O grau de associação linear é superior para o percentual de pessoas em domicílios com banheiro e água encanada, quando comparado ao serviço de coleta de lixo. Ambas são mantidas nas regressões, podendo haver eliminação posterior, caso se constate irrelevância para o modelo estimado.

Embora a metodologia proposta recomende a adoção de um critério de sustentabilidade, ou seja, um ponto de referência para as variáveis ambientais, aqui este procedimento não é realizado. Quanto maior o percentual de pessoas com acesso à água limpa e ao saneamento, espera-se que melhores sejam as condições de saúde, maior a frequência das crianças à escola e melhores as oportunidades de renda para os mais pobres.

O processo de seleção das variáveis para o modelo está apoiado na literatura existente (BANCO MUNDIAL, 1994; MOTTA, 1996; SEN, 2000; BOJÖ et al., 2001; DFID et al., 2002; SHYAMSUNDAR, 2002; MARKANDYA, 2006; PNUD, 1990; 2007; UNDP et al., 2005; COMIM, 2008; IBGE, 2008) e na disponibilidade de dados. Seguindo o modelo aplicado por Comim (2008) aos países, optou-se pela utilização de dados em corte transversal para os municípios paranaenses referentes ao ano 2000. Os microdados da Pesquisa Nacional de Amostra por Domicílios (PNAD) do IBGE poderiam ser utilizados para analisar o período mais recente, porém não permitiriam o recorte por município, considerado o mais adequado para o estudo das relações entre meio ambiente e pobreza, em função da heterogeneidade existente no Paraná.

Do conjunto de possíveis variáveis dependentes investigadas, foram selecionadas: mortalidade até 5 anos de idade; percentual de crianças de 7 a 14 anos que estão frequentando o curso fundamental; e intensidade da pobreza (Quadro 2). Considerando que o objetivo é investigar o nexo pobreza-meio ambiente, a ideia básica é escolher poucos indicadores para compor um índice para os municípios, procurando manter as mesmas dimensões do desenvolvimento e da pobreza humana e o foco em oportunidades para crianças e adultos (representada através da renda média das pessoas pobres, componente da intensidade da pobreza).

Para facilitar a leitura dos resultados e evitar problemas no momento da integração dos indicadores, torna-se necessário adaptar algumas variáveis extraídas do Atlas de Desenvolvimento Humano no Brasil (PNUD, 2003). Desta forma, garante-se a harmonização entre os indicadores, sendo que todos representam uma condição pior, quanto maior o valor. As adequações realizadas foram:

Percentual de crianças de 7 a 14 anos que não estão frequentando o curso fundamental (nfrqef) $=100$ - (percentual de crianças que estão frequentando o curso fundamental).

Percentual de pessoas que vivem em domicílios sem banheiro e água encanada (domsba) $=100$ - (percentual de pessoas que vivem em domicílios com banheiro e água encanada).

52 Distância que separa a renda domiciliar per capita média dos indivíduos pobres (definidos como os indivíduos com renda domiciliar per capita inferior a $\mathrm{R} \$ 75,50$ ) do valor da linha de pobreza medida em termos de percentual do valor dessa linha de pobreza. Este índice mostra quão pobres são as pessoas que se situam abaixo da linha da pobreza.

${ }^{53}$ Valor equivalente a meio salário mínimo vigente em agosto de 2000 (PNUD, 2003).

${ }^{54}$ Percentual de pessoas que vivem em domicílios com água encanada em pelo menos um de seus cômodos e com banheiro, definido como cômodo que dispõe de chuveiro ou banheira e aparelho sanitário (PNUD, 2003).

${ }^{55}$ Percentual de pessoas que vivem em domicílios em que a coleta de lixo é realizada diretamente por empresa pública ou privada, ou em que o lixo é depositado em caçamba, tanque ou depósito fora do domicílio, para posterior coleta pela prestadora do serviço. São considerados apenas os domicílios localizados em área urbana (PNUD, 2003). 
Percentual de pessoas que vivem em domicílios sem serviço de coleta de lixo (domscl) $=[100-$ (percentual de pessoas que vivem em domicílios urbanos com serviço de coleta de lixo)] * [(população urbana) / (população total)].

O Quadro 2 apresenta todas as variáveis empregadas nas regressões. Os modelos estimados, abrangendo as dimensões saúde, educação e renda, são respectivamente:

$$
\begin{aligned}
& {\text { Mort } 5 i_{i}}_{i}=\alpha_{i}+\beta_{1} \text { domsba }_{i}+\beta_{2} \text { domscl }_{i}+\beta_{3} \text { rendpc }_{i}+\beta_{4} \text { profef }_{i}+\beta_{5} \text { edufem }_{i}+e_{i} \\
& \text { Nfrqef }_{i}=\alpha_{i}+\beta_{1} \text { domsba }_{i}+\beta_{2} \text { domscl }_{i}+\beta_{3} \text { rendpc }_{i}+\beta_{4} \text { profef }_{i}+\beta_{5} \text { edufem }_{i}+e_{i} \\
& \text { Intpob }_{i}=\alpha_{i}+\beta_{1} \text { domsba }_{i}+\beta_{2} \text { domscl }_{i}+\beta_{3} \text { rendpc }_{i}+\beta_{4} \text { profef }_{i}+\beta_{5} \text { edufem }_{i}+e_{i}
\end{aligned}
$$

\begin{tabular}{|c|c|c|c|c|}
\hline & Variável & Descrição & Unidade & $\begin{array}{l}\text { Sinal esperado } \\
\text { do coeficiente }\end{array}$ \\
\hline \multirow{3}{*}{$\begin{array}{l}\text { Variáveis } \\
\text { dependentes } \\
\text { (dimensões } \\
\text { pobreza) }\end{array}$} & mort5i & Mortalidade até 5 anos de idade & $\begin{array}{l}\text { Mortes por } \\
1.000 \text { nascidos } \\
\text { vivos }\end{array}$ & $\begin{array}{l}\text { Variável de } \\
\text { interesse }\end{array}$ \\
\hline & nfrqef & \begin{tabular}{lcc}
\multicolumn{3}{l}{ Percentual de crianças de 7 a 14} \\
anos que não & estão \\
frequentando & 0 & curso \\
fundamental & &
\end{tabular} & Percentual & $\begin{array}{l}\text { Variável de } \\
\text { interesse }\end{array}$ \\
\hline & intpob & Intensidade da pobreza & Percentual & $\begin{array}{ll}\text { Variável } & \text { de } \\
\text { interesse }\end{array}$ \\
\hline \multirow{2}{*}{$\begin{array}{l}\text { Variáveis explicativas } \\
\text { (dimensão ambiental) }\end{array}$} & domsba & $\begin{array}{ll}\text { Percentual de pessoas } & \text { que } \\
\text { vivem em domicílios sem } & \text { sem } \\
\text { banheiro e água encanada }\end{array}$ & Percentual & Positivo \\
\hline & domscl & $\begin{array}{l}\text { Percentual de pessoas que } \\
\text { vivem em domicílios sem serviço } \\
\text { de coleta de lixo }{ }^{1}\end{array}$ & Percentual & Positivo \\
\hline \multirow{3}{*}{$\begin{array}{l}\text { Variáveis explicativas } \\
\text { (controle) }\end{array}$} & rendpc & Renda per capita & Reais de 2000 & Negativo \\
\hline & profef & $\begin{array}{l}\text { Percentual de professores do } \\
\text { fundamental residentes com } \\
\text { curso superior }\end{array}$ & Percentual & Negativo \\
\hline & edufem & $\begin{array}{l}\text { Percentual de mulheres sem } \\
\text { instrução e menos de um ano de } \\
\text { estudo }\end{array}$ & Percentual & Positivo \\
\hline
\end{tabular}

sendo $i$ o município (no caso do Paraná, 399 municípios no ano 2000).

Tendo especificado os modelos, torna-se importante comentar a direção de causalidade adotada no presente estudo das questões ambientais para as dimensões de pobreza, de acordo com a metodologia proposta por Comim (2008). Ainda que a literatura aponte a existência de relações bidirecionais, é reconhecido o maior peso da degradação e da falta de acesso a bens ambientais para as pessoas mais pobres (DURAIAPPAH, 1998; MARKANDYA, 2001). No caso de séries temporais, é possível aplicar o teste de causalidade de Granger, com base na ideia de que se $X$ causa $Y$, então variações em $X$ deveriam preceder variações em $Y$ (PINDYCK e RUBINFELD, 2004; GUJARATI, 2006). Duas hipóteses devem ser testadas: $X$ causa $Y$; e $Y$ não causa $X$. $O$ número de termos defasados a serem incluídos nos testes é de grande importância, uma vez que a direção da causalidade pode ser sensível à sua escolha. Como estão sendo utilizados dados em corte transversal para os municípios paranaenses e os indicadores estão disponíveis em base comparável apenas para os anos 1991 e 2000 - ou seja, somente uma defasagem -, não foi possível testar a causalidade. 
Cabe, ainda, um breve comentário sobre o problema de possível endogeneidade no modelo, pela inclusão da variável renda familiar per capita média, dado que maior renda pode resultar em melhora nos indicadores de pobreza e vice-versa. Levando em consideração o problema da simultaneidade, o método de variáveis instrumentais foi aplicado, a fim de comparar os estimadores com aqueles resultantes dos mínimos quadrados ordinários (MQO), já que a existência da simultaneidade gera estimadores inconsistentes e ineficientes por MQO. Como os resultados foram muito próximos, a decisão foi manter o método de MQO, adotando a simplicidade como princípio na escolha metodológica.

\section{Resultados das Regressões}

A Tabela 1 apresenta a estatística descritiva das variáveis incluídas nos modelos estimados, aplicados aos 399 municípios paranaenses constantes do Censo Demográfico de 2000. Como se pode observar por meio dos valores mínimo e máximo para cada variável das dimensões de pobreza e meio ambiente, o Paraná se caracteriza por fortes disparidades entre os municípios. Destaca-se a amplitude da mortalidade até 5 anos de idade, variando de 7,02 a 52,25 mortes por 1.000 nascidos vivos. Também é notável a heterogeneidade dos municípios em relação ao percentual de pessoas que vivem em domicílios sem banheiro e água encanada, de $0,46 \%$ a $69,20 \%$. Mesmo considerando os diferentes graus de urbanização, estes percentuais são muito expressivos.

\begin{tabular}{|c|c|c|c|c|}
\hline Variável & Média & $\begin{array}{l}\text { Desvio } \\
\text { padrão }\end{array}$ & Mínimo & Máximo \\
\hline Mortalidade até 5 anos de idade & 24,5491 & 7,6515 & 7,02 & 52,25 \\
\hline $\begin{array}{l}\text { Percentual de crianças de } 7 \text { a } 14 \text { anos que não estão frequentando o } \\
\text { curso fundamental }\end{array}$ & 9,4642 & 4,2877 & 2,96 & 29,06 \\
\hline Intensidade da pobreza & 41,0653 & 6,6771 & 26,47 & 62,85 \\
\hline $\begin{array}{l}\text { Percentual de pessoas que vivem em domicílios sem banheiro e } \\
\text { água encanada }\end{array}$ & 17,7311 & 14,8782 & 0,46 & 69,20 \\
\hline $\begin{array}{l}\text { Percentual de pessoas que vivem em domicílios sem serviço de } \\
\text { coleta de lix }{ }^{56}\end{array}$ & 3,0274 & 2,8798 & 0,09 & 22,13 \\
\hline Renda per capita & 202,0274 & 60,4872 & 86,00 & 619,82 \\
\hline $\begin{array}{l}\text { Percentual de professores do fundamental residentes com curso } \\
\text { superior }\end{array}$ & 23,9371 & 14,6630 & 0,15 & 71,53 \\
\hline $\begin{array}{l}\text { Percentual de mulheres sem instrução e menos de um ano de } \\
\text { estudo }\end{array}$ & 15,6593 & 6,0322 & 1,09 & 36,56 \\
\hline
\end{tabular}

Os resultados das estimações pelo método de mínimos quadrados ordinários (MQO) são mostrados na Tabela 2. Como a metodologia proposta por Comim (2008) recomenda, após executar a regressão e executá-la novamente apenas com as variáveis estatisticamente significativas, a tabela apresenta somente os coeficientes finais, significativos até $10 \%$.

\begin{tabular}{l|c|c|c}
\hline \multirow{2}{*}{ Variáveis explicativas } & \multicolumn{3}{|c}{ Variável dependente } \\
\cline { 2 - 4 } & $\begin{array}{c}\text { Mortalidade até 5 } \\
\text { anos de idade }\end{array}$ & $\begin{array}{c}\text { Percentual de crianças de 7 a 14 anos } \\
\text { que não estão frequentando o curso } \\
\text { fundamental }\end{array}$ & $\begin{array}{c}\text { Intensidade da } \\
\text { pobreza }\end{array}$ \\
\hline
\end{tabular}

\footnotetext{
${ }^{56}$ Considera apenas o serviço de coleta de lixo em domicílios urbanos.
} 


\begin{tabular}{|c|c|c|c|}
\hline $\begin{array}{l}\text { Percentual de pessoas que vivem } \\
\text { em domicílios sem banheiro e água } \\
\text { encanada }\end{array}$ & $\begin{array}{r}0,1575^{57} \\
(5,52)\end{array}$ & $\begin{array}{r}0,1797^{57} \\
(9,72)\end{array}$ & $\begin{array}{r}0,3008^{57} \\
(18,67)\end{array}$ \\
\hline $\begin{array}{l}\text { Percentual de pessoas que vivem } \\
\text { em domicílios sem serviço de coleta } \\
\text { de lixo }{ }^{58}\end{array}$ & $\begin{array}{r}0,3503^{57} \\
(2,98)\end{array}$ & & \\
\hline Renda per capita & & $\begin{array}{r}0,0122^{57} \\
(2,99)\end{array}$ & \\
\hline $\begin{array}{l}\text { Percentual de professores do } \\
\text { fundamental residentes com curso } \\
\text { superior }\end{array}$ & $\begin{array}{r}-0,0632^{57} \\
(-2,63)\end{array}$ & $\begin{array}{r}-0,0368^{57} \\
(-2,79)\end{array}$ & $\begin{array}{r}-0,0716^{57} \\
(-4,44)\end{array}$ \\
\hline $\begin{array}{l}\text { Percentual de mulheres sem } \\
\text { instrução e com menos de um ano } \\
\text { de estudo }\end{array}$ & $\begin{array}{r}0,3244^{57} \\
(5,09)\end{array}$ & $\begin{array}{r}0,1314^{57} \\
(3,22)\end{array}$ & \\
\hline Constante & $\begin{array}{r}17,0648^{57} \\
(11,90)\end{array}$ & $\begin{array}{r}2,6472^{59} \\
(1,68)\end{array}$ & $\begin{array}{r}37,4473^{57} \\
(58,91)\end{array}$ \\
\hline Observações & 399 & 399 & 399 \\
\hline $\mathrm{R}^{2}$ ajustado & 0,2943 & 0,3948 & 0,5697 \\
\hline
\end{tabular}

Tabela 2 - Resultados dos modelos de regressão estimados Obs.: entre parênteses, a estatística $t$ de Student.

$\mathrm{Na}$ primeira regressão, que tem como variável dependente a mortalidade até 5 anos de idade (equação 1), somente a renda per capita não é significativa. Todos os coeficientes apresentaram o sinal esperado: quanto maior o percentual de pessoas vivendo em domicílios sem banheiro e água encanada e sem serviço de coleta de lixo, maior a mortalidade infantil. A falta de acesso ao serviço de coleta de lixo em domicílios urbanos apresentou o maior coeficiente entre as variáveis explicativas $(0,3503)$. Nota-se também a influência da educação feminina sobre o indicador: quanto maior o percentual de mulheres sem instrução e com menos de um ano de estudo, maior a mortalidade até 5 anos.

$\mathrm{Na}$ segunda regressão, em que o percentual de crianças de 7 a 14 anos que não estão frequentando o curso fundamental é a variável dependente (equação 2), o serviço de coleta de lixo em domicílios urbanos não foi significativo. A ausência de banheiro e água encanada nos domicílios apresentou a maior influência sobre a frequência escolar $(0,1797)$, com sinal positivo, conforme previsto.

A última regressão, referente à intensidade de pobreza (equação 3), apresentou o maior impacto do percentual de pessoas vivendo em domicílios sem banheiro e água encanada sobre a variável dependente $(0,3008)$. Como na regressão anterior, o sinal é positivo e está de acordo com o esperado, e a variável relativa à coleta de lixo não foi significativa. $O R^{2}$ ajustado apresentou o maior valor entre todas as regressões de MQO (56,97\%).

O fator de inflação da variância (FIV) indicou ausência de multicolinearidade elevada ${ }^{60} \mathrm{em}$ todas as regressões. No entanto, pelos testes de Breusch-Pagan e de White, foi rejeitada a hipótese de variância constante dos erros (homocedasticidade) nas duas primeiras regressões, ou seja, para a mortalidade infantil e a frequência à escola. Para evitar estimadores ineficientes, em decorrência do problema de heterocedasticidade, as variâncias estimadas foram corrigidas usando White.

\footnotetext{
${ }^{57}$ Significância a $1 \%$

${ }^{58}$ Elaboração própria considera apenas o serviço de coleta de lixo em domicílios urbanos.

${ }^{59}$ Significância a $10 \%$.

${ }^{60}$ Uma variável é dita altamente colinear se o fator de inflação da variância (FIV) for maior que 10 (GUJARATI, 2006, p. 292).
} 


\section{Índice de Pobreza e Meio Ambiente (IPMA)}

Tendo os coeficientes estimados nas regressões, conforme resultados apresentados na Tabela 2, 0 próximo passo é o cálculo de um indicador composto para cada município.

Como todas as variáveis utilizadas nas regressões variam entre 0 e 100 , apontando pior condição quanto maior o valor, não foi necessário normalizá-las. Em seguida, foram calculados os fatores de ajuste, multiplicando-se cada variável ambiental pelo coeficiente da regressão, considerando somente as variáveis estatisticamente significativas (Tabela 2). O indicador composto para cada dimensão de pobreza é obtido por meio da multiplicação do fator de ajuste pela respectiva variável de pobreza. Desta forma, no caso dos municípios paranaenses, foram calculados os seguintes indicadores parciais:

$A_{11}=$ mortalidade até 5 anos de idade pela falta de acesso a banheiro e à água encanada = [(percentual de pessoas que vivem em domicílios sem banheiro e água encanada * 0,1575$)$ * (mortalidade até 5 anos de idade)]/100

$A_{12}=$ mortalidade até 5 anos de idade pela falta de acesso a serviço de coleta de lixo em domicílios urbanos $=[($ percentual de pessoas que vivem em domicílios urbanos sem serviço de coleta de lixo * 0,3503$){ }^{*}$ (mortalidade até 5 anos de idade)]/100

$A_{2}=$ redução na frequência escolar de crianças de 7 a 14 anos pela falta de acesso a banheiro e à água encanada $=[$ (percentual de pessoas que vivem em domicílios sem banheiro e água encanada * 0,1797) * (percentual de crianças de 7 a 14 anos que não estão frequentando o curso fundamental)]/100

$A_{3}=$ intensidade de pobreza pela falta de acesso a banheiro e à água encanada = [(percentual de pessoas que vivem em domicílios sem banheiro e água encanada * 0,3008) * (intensidade de pobreza)]/100

Como a mortalidade infantil foi a única variável dependente a apresentar associação significativa com as duas proxies ambientais empregadas no modelo (carência de acesso a banheiro e água encanada e a serviço de coleta de lixo), os respectivos indicadores $\left(A_{11}\right.$ e $\left.A_{12}\right)$ foram integrados por média simples:

$$
A_{1}=\frac{A_{11}+A_{12}}{2}
$$

A fim de possibilitar a integração dos indicadores, todos foram colocados em escala [0-1], sendo pior o indicador quanto mais próximo de 1. A transformação foi realizada adaptando-se a fórmula empregada no cálculo dos índices que compõem o IDH. Definidos os índices relativos a cada dimensão de pobreza - saúde $\left(A_{1}\right)$, educação $\left(A_{2}\right)$ e nível de vida (renda) $\left(A_{3}\right)$ - e dados os valores máximo e mínimo para cada dimensão, $A_{i j}^{\prime}$ é o índice normalizado relativo à dimensão $i$ para o município $j$ e é dado por:

$$
A_{i j}^{\prime}=\frac{\left(A_{i j}-\min _{j} A_{i j}\right)}{\left(\max _{j} A_{i j}-\min _{j} A_{i j}\right)}
$$

Por fim, o índice de pobreza e meio ambiente (IPMA) para cada município é a média aritmética simples dos índices normalizados em relação às três dimensões:

$$
I P M A_{j}=\frac{A_{1 j}^{\prime}+A_{2 j}^{\prime}+A_{3 j}^{\prime}}{3}
$$


Tomando-se como exemplo a capital paranaense, as variáveis extraídas do Atlas de Desenvolvimento Humano no Brasil (PNUD, 2003) relativos ao ano de 2000 foram: (a) percentual de pessoas que vivem em domicílios com banheiro e água encanada: 97,56\%; (b) percentual de pessoas que vivem em domicílios urbanos com serviço de coleta de lixo: 99,48\%; (c) grau de urbanização (população urbana/população total): 100,00\%; (d) mortalidade até 5 anos de idade: 24,26 mortes por 1.000 nascidos vivos; (e) percentual de crianças de 7 a 14 anos que estão frequentando 0 curso fundamental: $92,70 \%$; e (f) intensidade da pobreza: $43,76 \%$.

Os indicadores parciais, de acordo com as definições dadas anteriormente, são:

$A_{11}=$ mortalidade até 5 anos de idade pela falta de acesso a banheiro e à água encanada = $[(100-97,56) * 0,1575 * 2,43] / 100=0,0093$

$A_{12}=$ mortalidade até 5 anos de idade pela falta de acesso a serviço de coleta de lixo em domicílios urbanos $=[(100-99,48) * 0,3503 * 2,43] / 100=0,0044$

$A_{2}=$ redução na frequência escolar de crianças de 7 a 14 anos pela falta de acesso a banheiro e à água encanada $=\left[(100-97,56) * 0,1797^{*}(100-92,70)\right] / 100=0,0320$

$A_{3}=$ intensidade de pobreza pela falta de acesso a banheiro e à água encanada $=[(100-$ $97,56) * 0,3008 * 43,76] / 100=0,3211$

Do cálculo de cada um desses indicadores para todos os municípios foram extraídos os respectivos valores mínimo e máximo, utilizados para colocar os indicadores parciais em escalas [0-1], possibilitando a sua integração. Os indicadores normalizados são:

$$
\begin{aligned}
& A_{11}^{\prime}=\frac{0,0093-0,0011}{0,4840-0,0011}=0,0170 \\
& A_{12}^{\prime}=\frac{0,0044-0,0004}{0,2528-0,0004}=0,0160 \\
& A_{2}^{\prime}=\frac{0,0320-0,0045}{3,0498-0,0045}=0,0090 \\
& A_{3}^{\prime}=\frac{0,3211-0,0458}{11,5784-0,0458}=0,0239
\end{aligned}
$$

O indicador relativo à saúde $\left(A_{1}^{z}\right)$ é a média simples de $A_{11}^{z}$ e $A_{12}^{z}$ :

$$
A_{1}^{\prime}=\frac{0,0170+0,0160}{2}=0,0165
$$

Logo, o índice de pobreza e meio ambiente de Curitiba no ano 2000 é:

$$
I P M A_{\text {Curitiba }}=\frac{0,0165+0,0090+0,0239}{3}=0,016
$$

Torna-se importante sublinhar que o índice é melhor quanto mais próximo de zero. Neste sentido, o resultado para Curitiba apresenta um baixo grau de pobreza associado ao meio ambiente, o que é justificado pela elevada parcela da população vivendo em domicílios com banheiro e água encanada e com serviço de coleta de lixo.

\section{Análise dos resultados}

De acordo com os resultados das regressões apresentados na seção 4.3, as proxies ambientais utilizadas no modelo (percentual de pessoas que vivem em domicílios sem banheiro e água encanada; e 
percentual de pessoas que vivem em domicílios urbanos sem serviço de coleta de lixo) são significativas para explicar a pobreza nas dimensões saúde, educação e renda.

Até o momento, não se conhece trabalho similar realizado no Brasil, uma vez que a metodologia utilizada foi adaptada para o âmbito municipal, a partir de um novo modelo de indicadores de pobreza e meio ambiente, proposto por Comim (2008) e inicialmente aplicado a países. Cabe ressaltar que 0 modelo original sofreu importantes alterações, de modo a poder ser replicado em todos os municípios brasileiros, considerando a disponibilidade de dados e a premissa adotada neste artigo de que 0 desenvolvimento ocorre na esfera local (DINIZ, 2002; SERRA e PAULA, 2007), o que gera a necessidade de indicadores voltados para este nível.

Os resultados da aplicação do IPMA aos municípios paranaenses são analisados de duas formas. A primeira consiste no exame da distribuição dos municípios ao longo da escala do IPMA, lembrando que o índice varia entre 0 e 1, sendo maior o grau em que o meio ambiente afeta a pobreza (no caso, utilizando a falta de acesso a água encanada e banheiro como proxy referente ao saneamento) quanto mais próximo da unidade. Nesta distribuição, são avaliados os melhores e os piores classificados no ranking, buscando-se identificar características comuns entre os municípios. Adicionalmente, os resultados do IPMA são comparados aos do IPH-M, com o objetivo de verificar os efeitos da inclusão de uma perspectiva ambiental em um indicador multidimensional de pobreza.

O Gráfico 2 permite visualizar a distribuição dos municípios paranaenses por intervalos do IPMA. É interessante notar, em comparação com o IPH-M (Gráfico 1), a maior dispersão do IPMA, evidenciando diferenças significativas entre os municípios, que não aparecem quando as dimensões de longevidade, conhecimento e padrão de vida são agregadas no índice de pobreza humana. Portanto, os resultados contribuem para confirmar a relevância, apontada pela literatura, da inclusão de variáveis ambientais na análise da pobreza.

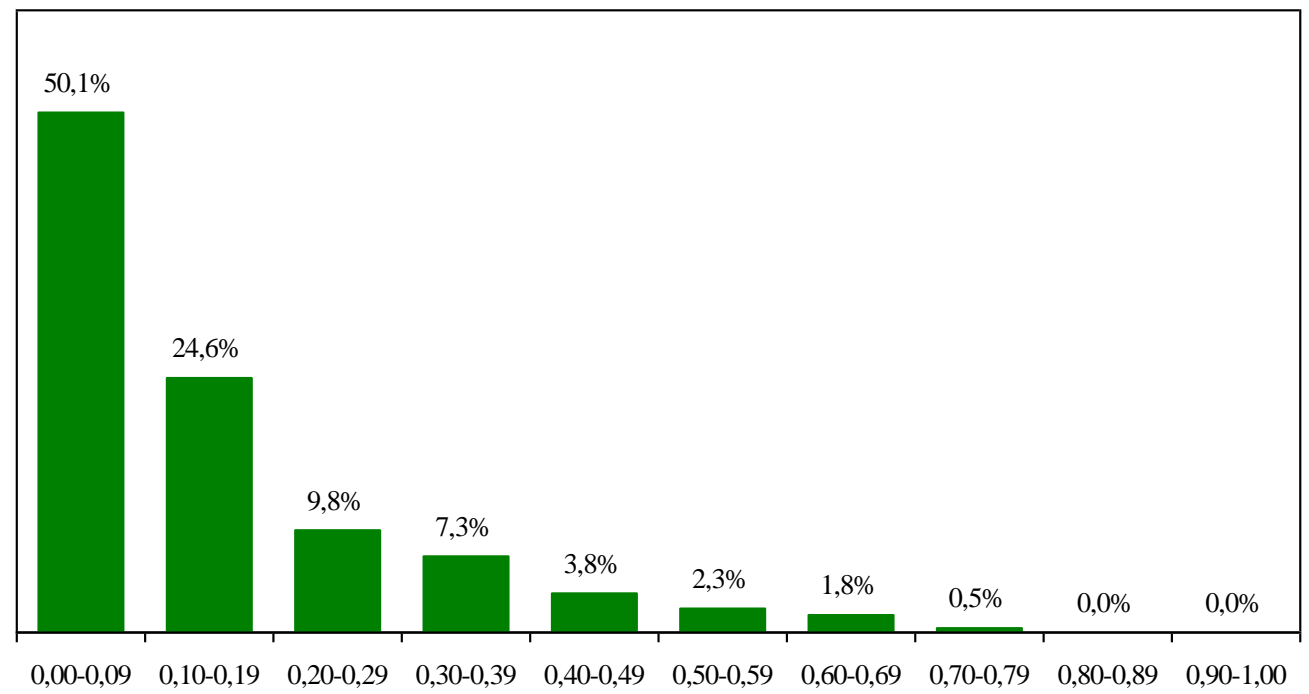

\footnotetext{
I IPMA 2000

Gráfico 2 - Distribuição dos municípios por intervalos de pobreza e meio ambiente, tema saneamento - Paraná (2000) Fonte: PNUD (2003). Elaboração dos autores.
}

No caso paranaense, a distribuição do IPMA é decrescente, sendo que a maior parte dos municípios foi classificada no estrato mais baixo, ou seja, 200 municípios $(50,1 \%)$ apresentaram baixo grau de pobreza determinada pelo meio ambiente. No extremo oposto, nenhum município foi classificado nos dois estratos superiores (IPMA maior ou igual a 0,80 , com alto grau de pobreza relacionada a determinantes ambientais). Porém, o problema de acesso inadequado à água e ao saneamento afeta de maneira significativa as condições de vida da população pobre no estado. Levando em conta os intervalos da metade superior da distribuição dos resultados, 33 municípios apresentaram IPMA maior ou igual a 0,40 . 
A Mesorregião Norte Central Paranaense, da qual fazem parte os municípios de Londrina e Maringá, tem a maior parcela de municípios com IPMA inferior a 0,10 (59 dos 79 municípios, ou 74,7\%). Também se destacam nas primeiras posições do ranking municípios das mesorregiões Noroeste, Oeste, Norte Pioneiro, Centro Ocidental Paranaense e Metropolitana de Curitiba. As mesorregiões Centro Oriental, Sudoeste e Sudeste Paranaense possuem mais municípios nas categorias intermediárias do IPMA. A Mesorregião Centro-Sul Paranaense não possui nenhum município classificado no primeiro estrato e concentra quatorze dos 33 municípios com os piores índices, ou seja, aproximadamente metade dos seus municípios se caracteriza por considerável grau de pobreza determinada pela dimensão ambiental. Na Figura 3, pode-se visualizar a distribuição dos municípios no estado, de acordo com o IPMA.

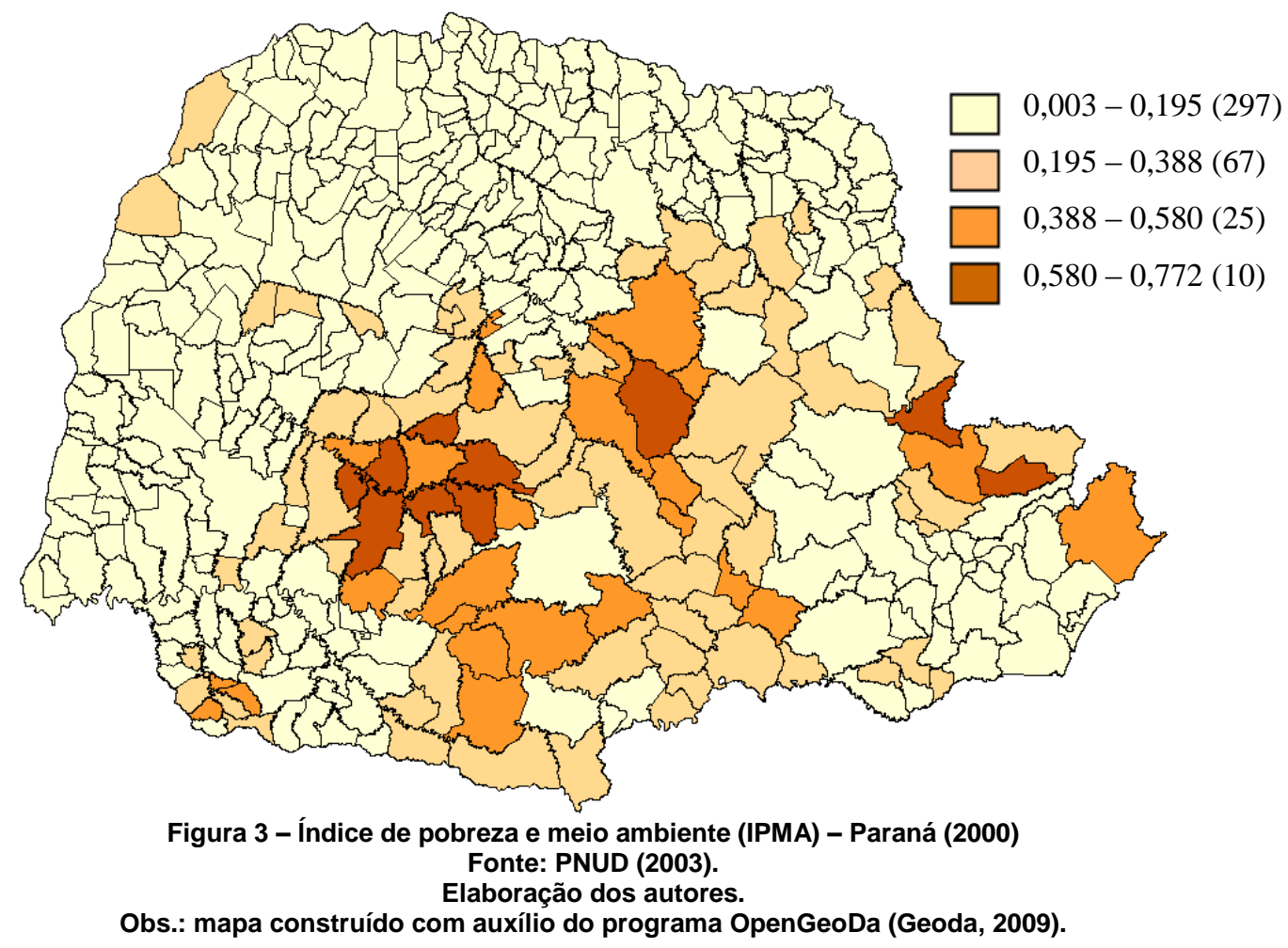

A maior diferenciação entre os municípios, verificada pelo IPMA em comparação com o IPH-M, também pode ser visualizada nos mapas (Figuras 3 e 2). Entre os municípios com pior IPH-M, pode-se notar que as variáveis ambientais apontam condições mais graves em alguns deles.

Um exame dos vinte melhores e dos vinte piores colocados entre os municípios no ranking do IPMA ressalta os contrastes entre as mesorregiões Norte Central e Centro-Sul Paranaense (Tabelas 3 e 4). A primeira concentra doze dos vinte melhores, enquanto, na segunda, estão dez dos vinte municípios com os piores índices. A Mesorregião Norte Central tem a segunda maior participação no PIB estadual (16,4\% em 2007), atrás apenas da Região Metropolitana de Curitiba. Possui uma economia diversificada e participação relevante nos três setores (agropecuária, indústria e serviços), sendo a maior em serviços. A Centro-Sul, além da menor participação no PIB paranaense $(3,0 \%$ em 2007), está baseada predominantemente na atividade agropecuária. 


\begin{tabular}{|c|c|c|c|c|c|}
\hline Município & Mesorregião & $\begin{array}{c}\text { Ordem IPMA } \\
\text { (do melhor ao pior) }\end{array}$ & $\begin{array}{l}\text { IPMA } \\
2000 \\
\end{array}$ & $\begin{array}{c}\text { Ordem IPH-M } \\
\text { (do melhor ao pior) }\end{array}$ & IPH-M 2000 \\
\hline Ivatuba & Norte Central Paranaense & 1 & 0,003 & 195 & 11,18 \\
\hline Itambé & Norte Central Paranaense & 2 & 0,003 & 126 & 9,51 \\
\hline Floresta & Norte Central Paranaense & 3 & 0,004 & 90 & 8,77 \\
\hline Maringá & Norte Central Paranaense & 4 & 0,005 & 11 & 4,73 \\
\hline Lobato & Norte Central Paranaense & 5 & 0,006 & 102 & 9,04 \\
\hline Pato Bragado & Oeste Paranaense & 6 & 0,006 & 6 & 4,04 \\
\hline Sarandi & Norte Central Paranaense & 7 & 0,007 & 46 & 7,37 \\
\hline São Jorge do Ivaí & Norte Central Paranaense & 8 & 0,008 & 103 & 9,05 \\
\hline Jussara & Noroeste Paranaense & 9 & 0,010 & 101 & 8,98 \\
\hline Flórida & Norte Central Paranaense & 10 & 0,010 & 107 & 9,08 \\
\hline Maripá & Oeste Paranaense & 11 & 0,011 & 3 & 3,49 \\
\hline Cambe & Norte Central Paranaense & 12 & 0,012 & 36 & 6,87 \\
\hline Cafelândia & Oeste Paranaense & 13 & 0,013 & 33 & 6,74 \\
\hline Entre Rios do Oeste & Oeste Paranaense & 14 & 0,013 & 1 & 2,86 \\
\hline Pinhais & Metropolitana De Curitiba & 15 & 0,014 & 7 & 4,49 \\
\hline Cornélio Procópio & Norte Pioneiro Paranaense & 16 & 0,014 & 63 & 8,09 \\
\hline Doutor Camargo & Norte Central Paranaense & 17 & 0,015 & 177 & 10,75 \\
\hline Mandaguari & Norte Central Paranaense & 18 & 0,016 & 77 & 8,36 \\
\hline Toledo & Oeste Paranaense & 19 & 0,016 & 17 & 5,51 \\
\hline lbiporã & Norte Central Paranaense & 20 & 0,016 & 55 & 7,89 \\
\hline
\end{tabular}

Tabela 3 - Ordenação dos vinte municípios com melhor colocação no ranking do IPMA e o respectivo IPH-M - Paraná (2000)

Fonte: Comim (2008) e PNUD (2003). Elaboração dos autores.

\begin{tabular}{|c|c|c|c|c|c|}
\hline Município & Mesorregião & $\begin{array}{c}\text { Ordem IPMA } \\
\text { (do melhor ao } \\
\text { pior) }\end{array}$ & $\begin{array}{l}\text { IPMA } \\
2000\end{array}$ & $\begin{array}{c}\text { Ordem IPH-M } \\
\text { (do melhor ao } \\
\text { pior) }\end{array}$ & $\begin{array}{c}\text { IPH-M } \\
2000\end{array}$ \\
\hline Godoy Moreira & Norte Central Paranaense & 380 & 0,484 & 396 & 20,48 \\
\hline Campina do Simão & Centro-Sul Paranaense & 381 & 0,485 & 257 & 12,65 \\
\hline São João do Triunfo & Sudeste Paranaense & 382 & 0,531 & 365 & 16,27 \\
\hline Guamiranga & Sudeste Paranaense & 383 & 0,537 & 301 & 13,71 \\
\hline Coronel Domingos Soares & Centro-Sul Paranaense & 384 & 0,541 & 318 & 14,22 \\
\hline Ortigueira & Centro Oriental Paranaense & 385 & 0,550 & 398 & 21,25 \\
\hline Fernandes Pinheiro & Sudeste Paranaense & 386 & 0,557 & 336 & 14,97 \\
\hline Cândido de Abreu & Norte Central Paranaense & 387 & 0,562 & 389 & 18,03 \\
\hline Inácio Martins & Centro-Sul Paranaense & 388 & 0,563 & 292 & 13,56 \\
\hline Rio Bonito do Iguaçu & Centro-Sul Paranaense & 389 & 0,573 & 351 & 15,61 \\
\hline Santa Maria do Oeste & Centro-Sul Paranaense & 390 & 0,587 & 377 & 17,16 \\
\hline Diamante do Sul & Oeste Paranaense & 391 & 0,604 & 394 & 19,79 \\
\hline Nova Laranjeiras & Centro-Sul Paranaense & 392 & 0,611 & 360 & 15,94 \\
\hline Doutor Ulysses & Metropolitana De Curitiba & 393 & 0,645 & 390 & 18,54 \\
\hline Reserva & Centro Oriental Paranaense & 394 & 0,653 & 387 & 17,83 \\
\hline Tunas do Paraná & Metropolitana De Curitiba & 395 & 0,658 & 397 & 20,52 \\
\hline Goioxim & Centro-Sul Paranaense & 396 & 0,671 & 349 & 15,41 \\
\hline Mato Rico & Centro-Sul Paranaense & 397 & 0,680 & 395 & 20,04 \\
\hline Laranjal & Centro-Sul Paranaense & 398 & 0,743 & 399 & 21,35 \\
\hline Marquinho & Centro-Sul Paranaense & 399 & 0,772 & 385 & 17,72 \\
\hline
\end{tabular}

Tabela 4 - Ordenação dos vinte municípios com pior colocação no ranking do IPMA e o respectivo IPH-M - Paraná (2000) Fonte: PNUD (2003). 
Um aspecto interessante é a diversidade dos municípios do Norte Central classificados nas primeiras posições do IPMA. O município de Ivatuba, próximo a Maringá, que foi o melhor colocado no ranking (IPMA de 0,003), tinha apenas 2,8 mil habitantes em 2000, com grau de urbanização de 68,9\%. Maringá, na quarta posição, contava com 288,7 mil habitantes (terceira maior população do estado em 2000) e população urbana de $98,4 \%$. Por outro lado, os municípios nas últimas posições do índice se caracterizam por pequeno porte populacional (máximo de 25,2 mil habitantes em Ortigueira) e baixo grau de urbanização (máximo de 40,1\% em Reserva). Cabe destacar não só que vários destes municípios se originaram de desmembramentos nas décadas de 1980 e 1990, como também a maior parcela da sua população ocupada está dedicada ao setor agropecuário.

A avaliação das proxies ambientais utilizadas no cálculo do IPMA reforça as diferenças observadas entre os indicadores econômicos dos municípios situados nas extremidades da distribuição dos resultados. Embora os municípios nas vinte primeiras posições do ranking sejam bastante heterogêneos quanto à população e ao grau de urbanização, todos se caracterizam por amplo acesso à água e ao saneamento: mínimo de $97,1 \%$ de pessoas vivendo em domicílios com banheiro e água encanada em Pinhais, na Região Metropolitana de Curitiba; e mínimo de 95,7\% de pessoas em domicílios urbanos com serviço de coleta de lixo em Toledo, no oeste paranaense. Entre os últimos vinte colocados, o percentual de pessoas vivendo em domicílios com banheiro e água encanada varia de $30,8 \%$ em Marquinho, último colocado no ranking (IPMA de 0,772), a 57,1\%, em Ortigueira. O indicador referente ao serviço de coleta de lixo em domicílios urbanos apresenta variação maior, de $44,2 \%$, em Goioxim, a 95,2\%, em Inácio Martins.

Na maior parte dos municípios, sobretudo naqueles com os piores resultados do IPMA, verificase que a maior influência dos determinantes ambientais sobre a pobreza, no caso paranaense, ocorre através da dimensão renda, refletida na intensidade de pobreza. Em suma, entre os indicadores utilizados no cálculo do IPMA, a distância entre a renda média dos pobres e a linha de pobreza (definida como meio salário mínimo) é mais afetada pelo meio ambiente que os indicadores de saúde e educação, e tende a ser maior quanto menor o acesso adequado à água e ao saneamento. Um aspecto importante a ser salientado é a não existência de uma falsa dicotomia, ou seja, do indivíduo ser pobre por não ter acesso ao saneamento ou, por ser pobre, é que não tem acesso ao saneamento. Na realidade, o resultado apenas indica que a melhoria das condições de saneamento pode contribuir para a saída da pobreza.

De modo geral, os resultados indicam que as questões ambientais no Paraná, medidas em função do acesso inadequado à água e ao saneamento, afetam principalmente as pessoas pobres em municípios de população predominantemente rural, onde a atividade agropecuária tem mais peso e a carência de serviços básicos é maior. Municípios com forte dependência da renda do setor agropecuário carregam riscos de oscilações em função do clima, do mercado e da política agrícola. Além disso, lavouras modernas, como a soja e o milho, principais grãos produzidos no estado, representam reduzido coeficiente de geração de emprego. Neste contexto, a capacitação das pessoas é fundamental, visando ao alcance da qualificação exigida pela mecanização crescente da agricultura e a criação de oportunidades de trabalho fora da agricultura de grande escala, como a produção agrícola familiar e atividades não agrícolas. Para isto, o acesso a serviços básicos relacionados à habitação, como água encanada e banheiro, é essencial, uma vez que reduz o tempo consumido com as atividades domésticas, sobretudo para as mulheres, possibilitando disponibilidade de tempo para educação e atividades geradoras de renda, além da contribuição direta para o bem-estar das famílias.

Por fim, é importante observar as mudanças na ordem dos municípios quando se compara o IPMA ao IPH-M. O coeficiente de correlação de Spearman $(0,5623)$ indica média associação entre a ordem dos dois índices. As diferenças são grandes e podem ser notadas já nas primeiras posições do ranking do IPMA. Por exemplo, o município de Ivatuba, melhor colocado no IPMA, é o 195 na ordem do IPH-M. A taxa de analfabetismo adulto (15,35\%) é o componente de maior peso para esta classificação relativa à pobreza humana. Entretanto, como Ivatuba apresenta elevada cobertura de serviços de saneamento, o grau em que o meio ambiente afeta a pobreza é muito próximo de zero.

Somente dois municípios mantiveram as mesmas posições nos rankings do IPMA e do IPH-M: Pato Bragado ( $6^{\circ}$ lugar) e Matelândia $\left(76^{\circ}\right)$, ambos da Mesorregião Oeste Paranaense. A maior variação positiva foi a de Inajá, na Mesorregião Noroeste, que avançou 306 posições, passando de $330^{\circ}$ lugar no IPH-M, com taxa de analfabetismo de adultos de $21,11 \%$, para $24^{\circ}$ no IPMA. De modo similar a Ivatuba, 0 bom resultado de Inajá se deve ao acesso à água e ao saneamento próximo de $100 \%$. Imbituva, localizada na Mesorregião Sudeste Paranaense, apresentou a maior variação negativa, perdendo 264 
posições, de $84^{\circ}$ lugar no ranking do IPH-M para $348^{\circ}$ no IPMA, com $36,35 \%$ da população vivendo em domicílios sem banheiro e água encanada.

O IPMA, utilizado como instrumento de análise, mostrou o vínculo existente entre meio ambiente e pobreza nos municípios paranaenses, relativo à falta de acesso à água e ao saneamento adequado. Quando comparado com o IPH-M, o índice evidenciou diferenças importantes entre os municípios, ao incorporar a perspectiva ambiental na avaliação da pobreza, considerando as dimensões de saúde, educação e renda. Assim sendo, o IPMA pode ser útil para a elaboração de políticas públicas direcionadas à população que sofre as maiores privações, nos casos em que a dimensão ambiental seja relevante.

\section{CONSIDERAÇÕES FINAIS}

A importância dos determinantes ambientais para várias dimensões de pobreza tem sido enfatizada pela literatura. Em geral, as pessoas que sofrem as maiores privações na sociedade estão mais expostas a ambientes de risco e têm suas oportunidades limitadas pela falta de acesso a bens ambientais adequados.

O Índice de Pobreza e Meio e Ambiente (IPMA) possibilitou a integração das variáveis ambientais e de pobreza e, consequentemente, permitiu analisar a relação existente entre as duas dimensões no Paraná, no âmbito municipal, ainda que esta análise estivesse restrita ao acesso à água e ao saneamento. Os resultados comprovaram o nexo pobreza-meio ambiente apontado pela literatura. Em comparação com o Índice de Pobreza Humana Municipal (IPH-M), o IPMA apresentou diferenças importantes entre os municípios paranaenses, evidenciando a significância da falta de acesso adequado a serviços de saneamento como um dos fatores determinantes da pobreza.

Ao incluir a dimensão ambiental na análise da pobreza, o IPMA apontou uma situação mais grave em alguns municípios. Em comum, os piores colocados no ranking do IPMA são municípios de pequeno porte populacional e baixo grau de urbanização, com maior parcela da população ocupada no setor agropecuário. A existência de água encanada e banheiro nos domicílios, empregadas como proxies ambientais na construção do IPMA, além dos benefícios diretos para o bem-estar das famílias, tem o potencial de melhorar as condições de saúde e disponibilizar tempo para a educação e atividades geradoras de renda.

\section{Referências}

BANCO MUNDIAL. World Development Report 1994: Infrastructure for development. New York: Oxford University Press, 1994.

BARBIER, E. B. Natural Resources and Economic Development. New York: Cambridge University Press, 2005. ch. 1.

Poverty, development, and ecological services. International Review of Environmental and

Resource Economics, n. 2, p. 1-27, 2008.

BOJÖ, J.; BUCKNALL, J.; HAMILTON, K.; KISHOR, N.; KRAUS, C.; PILLAI, P. Environment. In: WORLD BANK. Poverty Reduction Strategy Paper (PRSP) Sourcebook. 2001. ch. 11.

CHIARINI, T. Pobreza e meio ambiente no Brasil urbano. Economia-Ensaios, v. 20, n. 2, jul. - v. 21, n. 1, dez./2006.

COMIM, F. (Coord.). Poverty \& Environment Indicators. Report prepared for UNDP-UNEP under the Poverty and Environment Initiative. Capability and Sustainability Centre (CSC), St Edmund's College, Cambridge, March 2008.

DASGUPTA, P. The population problem: theory and evidence. Journal of Economic Literature, v. 33, p. 1879-1902, 1995. 428, 1996. The economics of the environment. Environment and Development Economics, v. 1, p. 387Human well-being and the natural environment. New York: Oxford University Press, 2001. 
DASGUPTA, S.; DEICHMANNN, U.; MEISNER, C.; WHEELER, D. Where is the poverty-environment nexus? Evidence from Cambodia, Lao PDR and Vietnam. World Development, v. 33, n. 4, p. 617-638, 2005.

DEPARTMENT FOR INTERNATIONAL DEVELOPMENT OF THE UNITED KINGDOM (DFID); DIRECTORATE GENERAL FOR DEVELOPMENT, EUROPEAN COMMISSION (EC); UNITED NATIONS DEVELOPMENT PROGRAMME (UNDP); THE WORLD BANK. Linking Poverty Reduction and Environmental Management - Policy Challenges and Opportunities. Washington: The World Bank, 2002.

DINIZ, C. C. Repensando a questão regional brasileira: tendências, desafios e caminhos. In: CASTRO, A. C. (Org.). Desenvolvimento em debate: painéis do desenvolvimento brasileiro II. Rio de Janeiro: Mauad/BNDES, 2002, v. 3, p. 239-274.

DINIZ, M. B.; OLIVEIRA JUNIOR, J. N.; TROMPIERI NETO, N.; DINIZ, M. J. T. Causas do desmatamento da Amazônia: uma aplicação do teste de causalidade de Granger acerca das principais fontes de desmatamento nos municípios da Amazônia Legal brasileira. Nova Economia, Belo Horizonte, v. 19, n. 1, p. 121-151, jan./abr. 2009.

DURAIAPPAH, A. K. Poverty and environmental degradation: a review and analysis of the nexus. World Development, v. 26, n. 12, p. 2169-2179, 1998.

FEARNSIDE, P. M. Conservation policy in Brazilian Amazonia: understanding the dilemmas. World Development, v. 31, n. 5, p. 757-779, 2003.

GEODA Center for Geospatial Analysis and Computation. Arizona State University. OpenGeoDa 0.9.8.14: GeoDa Center for Geospatial Analysis and Computation and Arizona Board of Regents, 19982009. Disponível em: <http://geodacenter.asu.edu/>.

GUJARATI, D. N. Econometria básica. Rio de Janeiro: Elsevier, 2006.

INSTITUTO BRASILEIRO DE GEOGRAFIA E ESTATÍSTICA (IBGE). Indicadores de desenvolvimento sustentável: Brasil 2008. Rio de Janeiro, 2008. (Estudos e pesquisas. Informação geográfica, n. 5).

Sistema IBGE de Recuperação Automática (SIDRA). 2009. Disponível em: <http://www.sidra.ibge.gov.br/>. Acesso em: 20 ago. 2009.

INSTITUTO DE ESTUDOS DO TRABALHO E SOCIEDADE (IETS). Dados+Tabulações: pobreza e indigência. 2013. Disponível em: <http://www.iets.org.br/>. Acesso em: 5 maio. 2013.

INSTITUTO PARANAENSE DE DESENVOLVIMENTO ECONÔMICO E SOCIAL (IPARDES). Leituras regionais: mesorregiões geográficas paranaenses: sumário executivo. Curitiba: IPARDES, 2004.

Os vários Paranás: identificação de espacialidades socioeconômico-institucionais como subsídio a políticas de desenvolvimento regional. Curitiba: IPARDES, 2006.

MARKANDYA, A. Poverty, environment and development. In: FOLMER, Henk et al. (Ed.). Frontiers of environmental economics. Cheltenham, UK; Northampton, MA, USA: Edward Elgar, 2001. ch. 8, p. 192213.

. Water Quality Issues in Developing Countries. In: LÓPEZ, R.; TOMAN,

M. A. Economic Development and Environmental Sustainability. New York: Oxford University Press, 2006. ch. 10.

MOTTA, R. S. da. Indicadores ambientais no Brasil: aspectos ecológicos, de eficiência e distributivos. Brasília: IPEA, 1996. (Texto para discussão n. 403).

PAGIOLA, S.; BISHOP, J.; LANDELL-MILLS, N.; (Eds.). Selling forest environmental services: marketbased mechanisms for conservation and development. London: Earthscan, 2004, ch. 15. 
PINDYCK, R. S.; RUBINFELD, D. L. Econometria: modelos e previsões. Rio de Janeiro: Elsevier, 2004.

PROGRAMA DAS NAÇÕES UNIDAS PARA O DESENVOLVIMENTO (PNUD). Human Development Report 1990. New York: Oxford University Press, 1990. Human Development Report 1997. New York: Oxford University Press, 1997. Relatório de Desenvolvimento Humano 2007/2008. New York, 2007. Atlas de Desenvolvimento Humano no Brasil. Brasília, 2003.

ROLIM, C. Um índice de pobreza humana municipal para o Brasil. Texto para discussão n. 17. Curitiba: PPGDE/UFPR, 2005.

SEN, A. K. Desenvolvimento como liberdade. São Paulo: Companhia das Letras, 2000.

SERRA, M. A.; PAULA, N. M. Desenvolvimento local: a experiência paranaense com os arranjos produtivos locais. In: MELO, R. L.; HANSEN, D. L. (Org.). Desenvolvimento regional e local: novas e velhas questões. São Cristóvão/SE: Editora Universidade Federal do Sergipe, 2007, p. 45-60.

SHYAMSUNDAR, P. Poverty-Environment indicators. World Bank, 2002. (Environmental Economics Series, Paper n. 84).

UNITED NATIONS. The Millennium Development Goals Report 2012. New York, 2012.

UNITED NATIONS DEVELOPMENT PROGRAMME (UNDP); UNITED NATIONS ENVIRONMENT PROGRAMME (UNEP); INTERNATIONAL INSTITUTE FOR ENVIRONMENT AND DEVELOPMENT (IIED); THE WORLD CONSERVATION UNION (IUCN); WORLD RESOURCES INSTITUTE (WRI). Assessing Environment's Contribution to Poverty Reduction. New York: UNDP, 2005.

VEIGA, J. E. A emergência socioambiental. São Paulo: Editora Senac São Paulo, 2007.

WORLD BANK. Poverty and the environment: understanding linkages at the household level. Washington, D.C., 2008.

WORLD HEALTH ORGANIZATION (WHO). The World Health Report 2002: reducing risks, promoting healthy life. Geneva, 2002. 